\title{
Synthesis and Vacuum Ultraviolet Spectral Properties of Nano-scaled Phosphors
}

\author{
Yuhua WANG, Zhaofeng WANG, Xue YU and Qizheng DoNG \\ Department of Materials Science, School of Physical Science and Technology, Lanzhou University, \\ Lanzhou, 730000, PR China \\ E-mail:wyh@lzu.edu.cn.
}

\begin{abstract}
The nano-scaled red phosphor $\mathrm{YBO}_{3}: \mathrm{Eu}^{3+}$, green phosphor $\mathrm{ZnSiO}_{4}: \mathrm{Mn}^{2+}$ and blue phosphor $\mathrm{BaMgAl}_{10} \mathrm{O}_{17}$ : $\mathrm{Eu}^{2+}$ were synthesized by wet-chemical techniques. The morphologies and spectral properties of the three nano-phosphors under $147 \mathrm{~nm}$ excitation were investigated. For $\mathrm{YBO}_{3}: \mathrm{Eu}^{3+}$, nano-sheets was obtained by solvent-thermal process, which reached $78.8 \%$ of the commercial red phosphor on emission intensity and exhibited better color purity than the latter. For $\mathrm{ZnSiO}_{4}: \mathrm{Mn}^{2+}$, different morphologies were obtained by hydrothermal method with varying ratio of CTAB to TEOS, among which the nano-spheres presented the strongest emission intensity and reached $86 \%$ of that of the commercial green phosphor. For $\mathrm{BaMgAl}_{10} \mathrm{O}_{17}$ : $\mathrm{Eu}^{2+}$, nano-rods were acquired using sol-gel process, which exhibited $78.15 \%$ of the commercial blue phosphor on emission intensity and the low $y$ value of color coordinates, which indicated that the nano-rods were efficient for restricting the deteriorate during application.
\end{abstract}

Key Words : Synthesis, nano-phosphor, VUV

\section{Introduction}

The plasma display panel (PDP) was known as one of the promising flat panel display devices which utilized vacuum ultraviolet (VUV) exciting the phosphors, and a visible emission was generated ${ }^{[1]}$. The representative tricolor commercial phosphors for PDP were (Y, Gd) $\mathrm{BO}_{3}: \mathrm{Eu}^{3+}, \mathrm{ZnSiO}_{4}: \mathrm{Mn}^{2+}$ and $\mathrm{BaMgAl}_{10} \mathrm{O}_{17}$ : $\mathrm{Eu}^{2+}$ (BAM) due to their strong emission intensity and good color purity. However, there are still some deficiencies in these phosphors: The color purity of $(\mathrm{Y}, \mathrm{Gd}) \mathrm{BO}_{3}$ : $\mathrm{Eu}^{3+}$ was poor and the decay time of $\mathrm{ZnSiO}_{4}: \mathrm{Mn}^{2+}$ was too long for the application, while the degradation of $\mathrm{BaMgAl}_{10} \mathrm{O}_{17}: \mathrm{Eu}^{2+}$ was an outstanding problem during panel manufacture ${ }^{[2]}$.

Recently, many researchers have focused on the preparation and luminescent properties of nano-phosphors because of their small size effect, surface effect, and the quantum size effect, which made them promising to present different optical and electrical properties compared with bulk phosphors ${ }^{[3]}$. Besides, to meet the requirement of the PDP manufacture procedure, nano-phosphors were convenient to brush the panel and they could get higher resolution to make the pictures more vivid.

With the expectation of improving the physical, chemical and luminescent properties of ordinary particles, many soft-chemical techniques have been adopted to synthesize nano-particles on the account of their good mixing of starting materials and relatively low reaction temperature ${ }^{[4]}$. In this work, the nano-scaled $\mathrm{YBO}_{3}$ : $\mathrm{Eu}^{3+}, \mathrm{ZnSiO}_{4}: \mathrm{Mn}^{2+}$ and $\mathrm{BaMgAl}_{10} \mathrm{O}_{17}: \mathrm{Eu}^{2+}$ were respectively prepared by different soft-chemical methods, which were solvent-thermal, hydrothermal method and sol-gel process. Their morphologies and spectral properties under VUV excitation were investigated and discussed.

\section{Experiments}

\section{$2.1 \mathrm{YBO}_{3}: \mathrm{Eu}^{3+}$ nano-phosphor}

$\mathrm{YBO}_{3}: \mathrm{Eu}^{3+}$ nano-phosphor was synthesized by solvent-thermal method. The starting materials were $\mathrm{Y}_{2} \mathrm{O}_{3}(99.99 \%), \mathrm{Eu}_{2} \mathrm{O}_{3}$ (99.99\%) and $\mathrm{H}_{3} \mathrm{BO}_{3}(99.5 \%)$. Stoichiometric amounts of $\mathrm{Y}_{2} \mathrm{O}_{3}$ (95 wt \%) and $\mathrm{Eu}_{2} \mathrm{O}_{3}(5 \mathrm{wt} \%)$ were dissolved in diluted nitric acid by heating, and drying to get a mixture of $\mathrm{Y}\left(\mathrm{NO}_{3}\right)_{3}$ and $\mathrm{Eu}\left(\mathrm{NO}_{3}\right)_{3}$. Stoichiometric amount of $\mathrm{H}_{3} \mathrm{BO}_{3}$ was added in the mixture. The mixture was dissolved in $50 \mathrm{~mL}$ of mixed water and ethanol hybrid solution (the relative volume ratio of water to ethanol are adjusted to $1: 0,1: 1,1: 2$ and $1: 3$, respectively) under ultrasonic mixing for $1 \mathrm{~h}$. The initial $\mathrm{pH}$ value was adjusted to 8 with ammonia, since the reaction was a process of producing $\mathrm{H}^{+}$and weak alkaline conditions were propitious to reaction production. The solution was transferred into a $100 \mathrm{~mL}$ Teflon-lined, stainless steel autoclave. The solution was heated at $230^{\circ} \mathrm{C}$ and the reaction time was $3 \mathrm{~h}$. White precipitates were collected, filtered and washed with distilled water and ethanol several times, and dried in an oven at $80^{\circ} \mathrm{C}$ to get the final product.

\section{$2.2 \mathrm{ZnSiO}_{4}: \mathrm{Mn}^{2+}$ nano-phosphor}

$\mathrm{Zn}_{2} \mathrm{SiO}_{4}: \mathrm{Mn}^{2+}$ nano-phosphor was synthesized in an autoclave equipped with a Teflon reaction vessel by hydrothermal method. All the reagents are of analytical grade. $\mathrm{Zn}\left(\mathrm{CH}_{3} \mathrm{COO}\right)_{2} \cdot 2 \mathrm{H}_{2} \mathrm{O}$ $(99.0 \%), \mathrm{Mn}\left(\mathrm{CH}_{3} \mathrm{COO}\right)_{2} \cdot 4 \mathrm{H}_{2} \mathrm{O}(99.0 \%)$ and $\left(\mathrm{C}_{2} \mathrm{H}_{5} \mathrm{O}\right)_{4} \mathrm{Si}\left(\mathrm{SiO}_{2}\right.$, $28.4 \%$ ) (TEOS) were used as sources of zinc, manganese, and silicon, respectively. In a typical procedure, firstly, TEOS was dissolved in a mixed solution of distilled water and ethanol, 
ammoniun hydroxide was added as a catalyst for the hydrolysis of TEOS with vigorous stirring for an hour. $\mathrm{Zn}\left(\mathrm{CH}_{3} \mathrm{COO}\right)_{2} \cdot 2 \mathrm{H}_{2} \mathrm{O}$ and $\mathrm{Mn}\left(\mathrm{CH}_{3} \mathrm{COO}\right)_{2} \cdot 4 \mathrm{H}_{2} \mathrm{O}$ was dissolved in the distilled water and stirred continuously until complete dissolution occurred. Then the TEOS solution was slowly added to the aqueous solution of $\mathrm{Zn}\left(\mathrm{CH}_{3} \mathrm{COO}\right)_{2}$ and $\mathrm{Mn}\left(\mathrm{CH}_{3} \mathrm{COO}\right)_{2}$. After being stirred for half an hour, the mixed solution was transferred into the Teflon reaction vessel in the autoclave and heated at different temperature for $2 \mathrm{~h}$. After cooling down to room temperature naturally, the resultant products were collected by filtration, followed by washing and drying. To control the morphology and the particle sizes of the phosphor, cetyl-tri-methyl-ammonium bromide (CTAB) as the surfactant was added to the solution of $\mathrm{Zn}\left(\mathrm{CH}_{3} \mathrm{COO}\right)_{2}$ and $\mathrm{Mn}\left(\mathrm{CH}_{3} \mathrm{COO}\right)_{2}$. The final phosphor obtained through the same procedure of hydrothermal method mentioned above.

\section{$2.3 \mathrm{BaMgAl}_{10} \mathrm{O}_{17}: \mathrm{Eu}^{2+}$ nano-phosphor}

$\mathrm{BaMgAl}_{10} \mathrm{O}_{17}: \mathrm{Eu}^{2+}$ was synthesized by sol-gel process. The starting materials $\mathrm{Eu}_{2} \mathrm{O}_{3}(99.99 \%), \mathrm{Al}\left(\mathrm{NO}_{3}\right)_{3} \cdot 9 \mathrm{H}_{2} \mathrm{O}(99.0 \%)$, $\mathrm{Ba}$ $\left(\mathrm{NO}_{3}\right)_{2}(99.5 \%)$ and $\mathrm{Mg}\left(\mathrm{NO}_{3}\right)_{2} \cdot 6 \mathrm{H}_{2} \mathrm{O}(99.0 \%)$ were weighted as the nominal composition of $\mathrm{Ba}_{0.9} \mathrm{MgAl}_{10} \mathrm{O}_{17}: 0.1 \mathrm{Eu}^{2+}$. Then, citric acid were dissolved in deionized water and adjusted $\mathrm{pH}$ value to 3 by $\mathrm{NH}_{3} \cdot \mathrm{H}_{2} \mathrm{O}$. And then a stoichiometric amount of starting materials was dissolved in the citric solution. After all of the materials were dissolved, they were adjusted the $\mathrm{pH}$ value to 5 and heated to $60^{\circ} \mathrm{C}$ with ceaselessly stirring about half an hour to gain the sol. The sol was placed in room temperature for about $40 \mathrm{~min}$ in succession. Then it was dried in a muffle oven at $120^{\circ} \mathrm{C}$ and the volume of the gel expanded greatly and the puffy and porous dried gel was obtained. Finally the gel was grinded in an agate mortar and sintered at the temperature range of $850^{\circ} \mathrm{C}$ to $1300^{\circ} \mathrm{C}$ for $4 \mathrm{~h}$ under a reducing atmosphere $\left(5 \% \mathrm{H}_{2} / \mathrm{N}_{2}\right.$ mixture gas $)$ to obtain the product.

\subsection{Characterizations}

The X-ray diffraction (XRD) patterns were obtained on a Rigaku D/max-2400 X Ray diffractometer. The morphology of the powders was examined by Transmission Electron Microscopy (TEM) performed with a Hitachi H-800 transmission electron microscope using an accelerating voltage of $200 \mathrm{kV}$ and JEOL5600 Scanning Electron Microscope (SEM). The emission spectra were measured at room temperature by FLS-920T fluorescence spectrophotometer with a VM-504-type vacuum monochromator. A deuterium lamp was used as the lighting source.

\section{Results and discussions}

\section{1 $\mathrm{YBO}_{3}: \mathrm{Eu}^{3+}$ red nano-phosphor}

Figure 1 shows XRD patterns of the $\mathrm{YBO}_{3}: \mathrm{Eu}^{3+}$ samples synthesized with different ratios of water to solvent. All the diffraction peaks could be indexed to the JCPDF card (No. 831205), and there is no second phase observed. As shown in the Figure 1, the relative intensity of the diffraction peaks for the solvent-thermal ( $\mathrm{SO}$ ) samples are different from the sample prepared by hydrothermal reaction (HR, the 1:0 samples). The (002) peak is the strongest for the HR samples but the (100) peak becomes strongest when the solvent was introduced in the reaction systems, indicating the appearance of a preferred orientation. Moreover, the broadening of the diffraction peaks in Figure 1 indicates that the crystallite size of sample is small. By Scherrer formula, the average crystallite sizes of the samples are $25.8 \mathrm{~nm}$, $17.6 \mathrm{~nm}, 17.7 \mathrm{~nm}$ and $23 \mathrm{~nm}$, corresponding to the different synthesis conditions (the ratio of water to ethanol hybrid) as 1:0,
1:1, $1: 2$ and 1:3, respectively. This result suggests that the addition of ethanol hybrid in the synthesis will restrict the growth of the grains.

The TEM photographs of the SO and HR samples are shown in Figure 2. In Figure 2(a), we could find that the HR particles are

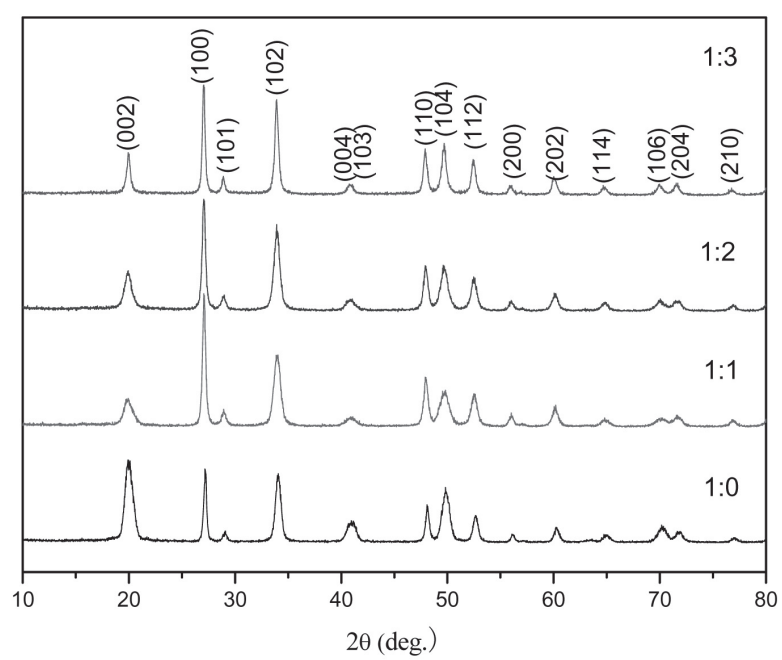

Figure 1 XRD patterns of the $\mathrm{YBO}_{3}: \mathrm{Eu}^{3+}$ samples prepared with different ratios of water to solvent.
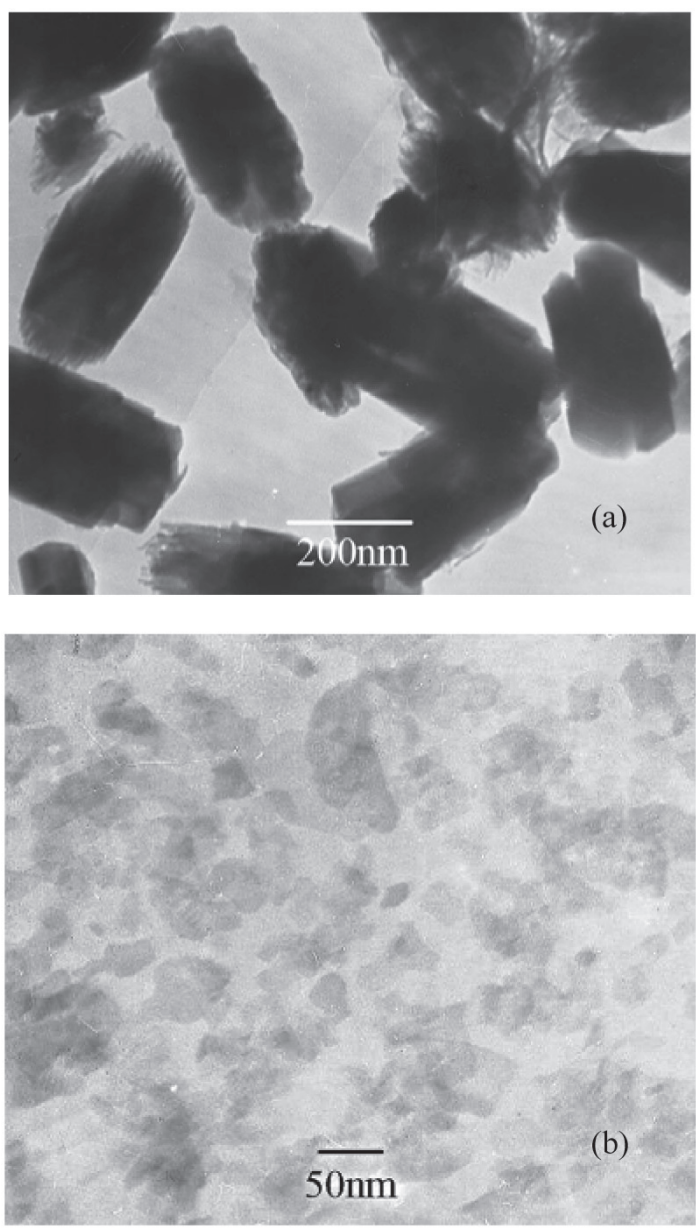

Figure 2 TEM images of $\mathrm{YBO}_{3}: \mathrm{Eu}^{3+}$ phosphors prepared by different reation

(a) HR Samples; (b) SO samples. 
rod-like with the average size of $150 \mathrm{~nm}$ in diameter and $300 \mathrm{~nm}$ in length. This differs from calculated results from XRD, indicating that a particle in this sample is polycrystalline and consists of several monocrystalline particles. By the addition of solvent, the morphology changes into nano-sheets with the size about $50 \mathrm{~nm}$, which is consistent with the results of the XRD patterns. The particles in SO sample also represent better dispersion than that of HR samples. This result indicates that adding solvent will be conducive to decrease grain size and improve dispersion of the sample particle. The possible reason may be the alternation of the dielectric constant of the solution. With the addition of solvent to the aqueous solution, the dielectric constant of the mixed solvent decreased, which led to the decrease in solubility of the reaction materials during the crystallization process. As a result, it would lead to the formation of smaller particles. ${ }^{[5-6]}$

Under $147 \mathrm{~nm}$ excitation, the emission spectra of the SO samples with different ratios of water to solvent are shown in Figure 3. All spectra consist of sharp lines ranging from 580 to $700 \mathrm{~nm}$, which are associated with the transitions from the excited ${ }^{5} \mathrm{D}_{0}$ level to ${ }^{7} \mathrm{~F}_{\mathrm{J}}$ $(\mathrm{J}=1,2,3,4)$ levels of $\mathrm{Eu}^{3+}$ activators ${ }^{[7]}$. The major emissions of $\mathrm{YBO}_{3}: \mathrm{Eu}^{3+}$ is at $592 \mathrm{~nm}\left({ }^{5} \mathrm{D}_{0} \rightarrow{ }^{7} \mathrm{~F}_{1}\right)$ and 611 and $627 \mathrm{~nm}\left({ }^{5} \mathrm{D}_{0} \rightarrow{ }^{7} \mathrm{~F}_{2}\right)$. It is observed that the strongest red emission is observed for the sample prepared at the water to solvent ratio of $1: 2$, and the PL intensity of sample $d$ is obviously lower than the others. It can be due to the existence of a small amount of $\mathrm{OH}^{-}$coordinated to lanthanide ions at the surface of phosphors prepared by the wet chemical method. Adding excessive amount organic solvent (over 1:3) lead to large amount of $\mathrm{OH}^{-}$adhering on the surface of phosphor, which results in the poor PL intensity ${ }^{[8]}$. As can be seen in the figure, the ${ }^{5} D_{0} \rightarrow{ }^{7} F_{2}$ emission increased and ${ }^{5} D_{0} \rightarrow{ }^{7} F_{1}$ emission decreased with solvent added. This must be associated with particle size of samples (observed before). It is well known that the relative intensity of ${ }^{5} D_{0} \rightarrow{ }^{7} F_{1}$ transitionor ${ }^{5} D_{0} \rightarrow{ }^{7} F_{2}$ transition depends strongly on the local symmetry of $\mathrm{Eu}^{3+}$. When the particle size decreases, smaller particles have higher effective surface area and larger lattice distortion, leading to the formation of $\mathrm{Eu}^{3+}$ ions occupying lower symmetry sites. This will increase the transition probability of ${ }^{5} D_{0} \rightarrow{ }^{7} F_{2}$ and thus improve color purity ${ }^{[9]}$. It was found that the ratio of red emission $(611 \mathrm{~nm})$ intensity to

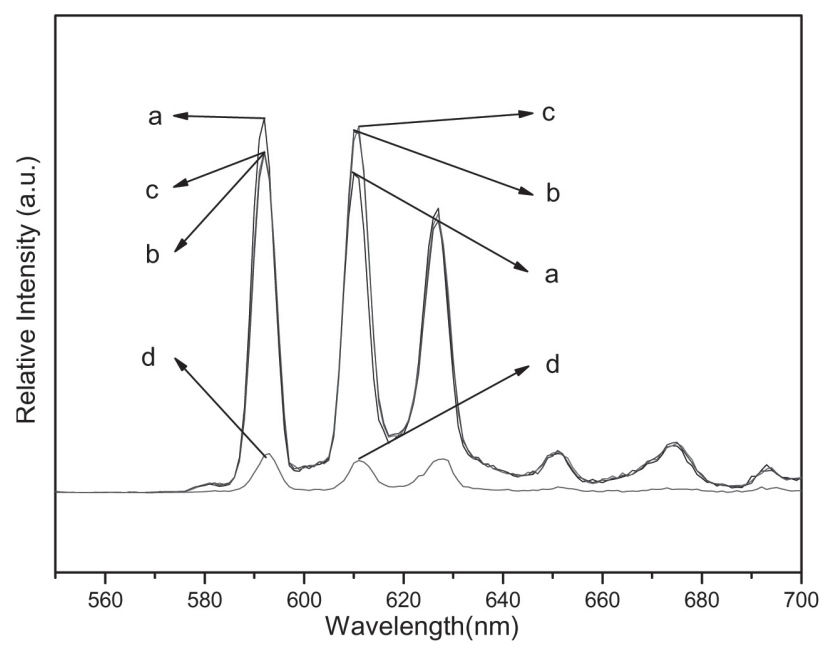

Figure 3 Emission spectra of $\mathrm{YBO}_{3}: \mathrm{Eu}^{3+}$ nano-phosphors prepared at different ratios of water to solvent.

(a) $1: 0$; (b) $1: 1$; (c) $1: 2 ;$ (d) $1: 3\left(\lambda_{\text {ex }}=147 \mathrm{~nm}\right)$. orange emission $(592 \mathrm{~nm})$ intensity $(\mathrm{R} / \mathrm{O})$ is 1.11 , which predicts that the SO sample (solvent at 1:2) has the highest color purity.

\section{2 $\mathrm{ZnSiO}_{4}: \mathrm{Mn}^{2+}$ green nano-phosphor}

Figure 4 shows the XRD patterns of the $\mathrm{Zn}_{2} \mathrm{SiO}_{4}: 0.06 \mathrm{Mn}^{2+}$ phosphors prepared at different reaction temperatures. All the diffraction peaks can be indexed to pure hexagonal structured $\mathrm{Zn}_{2} \mathrm{SiO}_{4}$ (JCPDF card, No. 37-1485). The $\mathrm{Zn}_{4} \mathrm{Si}_{2} \mathrm{O}_{7}(\mathrm{OH})_{2} \mathrm{H}_{2} \mathrm{O}$ is not detected as that reported by Ref. ${ }^{[10]}$ in the hydrothermal procedure below $280^{\circ} \mathrm{C}$, which means that there is no intermediate phase in our samples prepared by hydrothermal procedure even at a low reaction temperature. Furthermore. the XRD result shows that pure hexagonal-structured $\mathrm{Zn}_{2} \mathrm{SiO}_{4}$ can be obtained at the low temperature of $140^{\circ} \mathrm{C}$, which is lower than the temperature of $220^{\circ} \mathrm{C}$ reported by Wan et al. ${ }^{[11]}$ and much lower than that using the conventional solid-state reaction method. The average crystallite sizes estimated from the Scherrer equation indicated all the samples were in nanoscaled, and $\mathrm{Zn}_{2} \mathrm{SiO}_{4}: \mathrm{Mn}^{2+}$ sample prepared at $220^{\circ} \mathrm{C}$ represents the best crystallinity.

When CTAB was used in the hydrothermal procedure as the surfactant molecules, it was found that the size and the morphology of the $\mathrm{Zn}_{2} \mathrm{SiO}_{4}$ : $\mathrm{Mn}^{2+}$ phosphors could be controlled as shown in Figure 5(a)-(d). When the CTAB/TEOS $=0.01$ was adopted, the rod-like particles show the trends to the sphere-like shaped (Figure $5(\mathrm{~b})$ ). This is an interim morphology from rod-like to spheres. When the concentration of CTAB increased to CTAB/TEOS $=0.05$, TEM micrograph (Figure 5(c)) shows that the willemite phosphors are nano-spheres with the diameter about $60 \mathrm{~nm}$. The nanoparticles dispersed well without agglomeration. When larger amount of CTAB are introduced, aggregation of the nanoparticles can be observed in the final products. It was known that the surfactant molecules could adsorb on the surface of particles and stabilize the particle by either electrostatic repulsion or steric force. ${ }^{[12]}$ Therefore, the particle size and shape of $\mathrm{Zn}_{2} \mathrm{SiO}_{4}: \mathrm{Mn}^{2+}$ nanoparticles would be limited and controlled by the presence of $\mathrm{CTAB}$ in the hydrothermal procedure as shown in Figure 5.

The relative intensities of $\mathrm{Zn}_{2} \mathrm{SiO}_{4}: 0.06 \mathrm{Mn}^{2+}$ samples at different reaction temperatures under the $147 \mathrm{~nm}$ excitation are given in Figure 6(a). The strongest broad band emission at about $523 \mathrm{~nm}$ was observed, which is attributed to the ${ }^{4} \mathrm{~T}_{1} \rightarrow{ }^{6} \mathrm{~A}_{1}$ transition of $\mathrm{Mn}^{2+}$. It shows that the luminescence intensity increases when

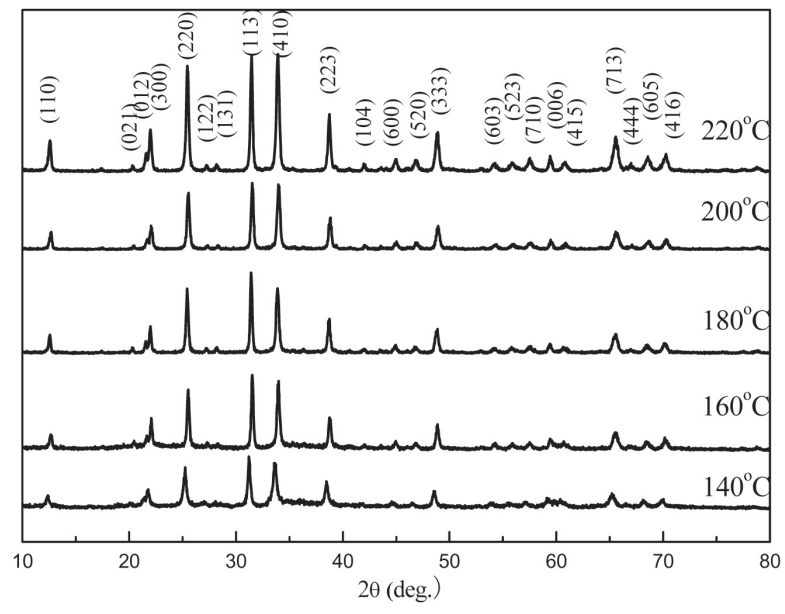

Figure 4 XRD patterns of the $\mathrm{Zn}_{2} \mathrm{SiO}_{4}: 0.06 \mathrm{Mn}^{2+}$ samples prepared at different reaction temperatures. 

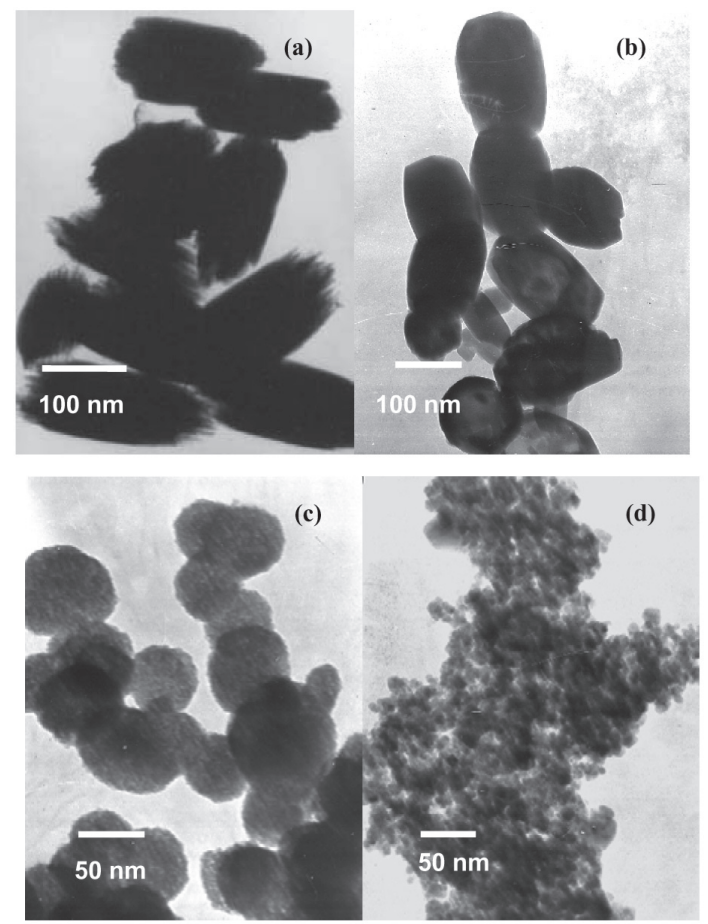

Figure 5 TEM micrographs of the $\mathrm{Zn}_{2} \mathrm{SiO}_{4}: 0.06 \mathrm{Mn}^{2+}$ samples synthesized at different conditions.

(a) Without CTAB, (b) CTAB/TEOS $=0.01$, (c) $\mathrm{CTAB} / \mathrm{TEOS}=$ 0.05 , (d) $\mathrm{CTAB} / \mathrm{TEOS}=0.20$.
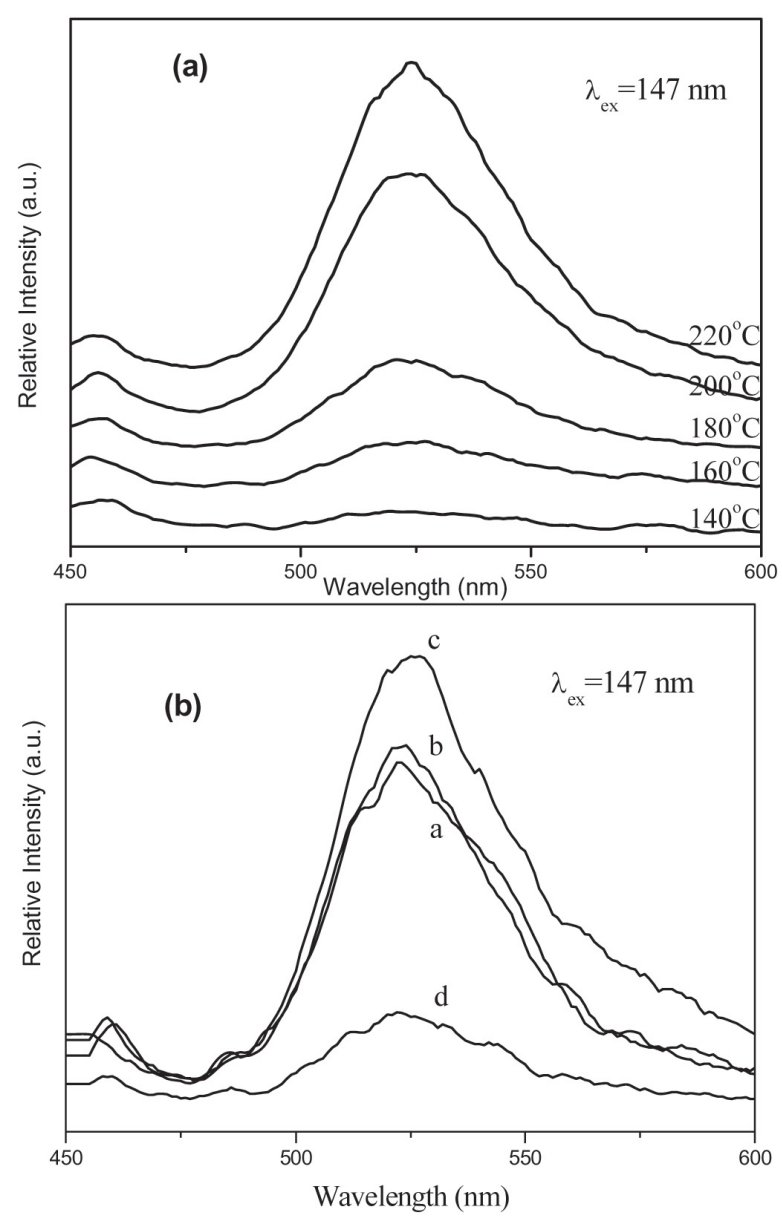

Figure 6 Emission spectra of $\mathrm{Zn}_{2} \mathrm{SiO}_{4}: 0.06 \mathrm{Mn}^{2+}$ phosphors (a) synthesized at different reaction temperature, (b) different ratio of CTAB to TEOS of samples a-d. the temperature increases. This phenomenon would be ascribed to the higher crystallinity according to the XRD results as discussed previously.

The PL intensity among different morphology of the phosphors was also investigated. Figure 6(b) presents emission spectra for the samples with different morphology under VUV excitation. The green luminescence is the conventional green of $\mathrm{Zn}_{2} \mathrm{SiO}_{4}$ : $\mathrm{Mn}^{2+}$ phosphor, occurring at about $523 \mathrm{~nm}$. As can be seen in Figure 6(b), change in morphology of phosphors has a certain extent influence on their luminescent intensity. It can be seen that the highest PL intensity was obtained when the $\mathrm{Zn}_{2} \mathrm{SiO}_{4}$ : $\mathrm{Mn}^{2+}$ phosphor has uniform spherical morphology (sample c) due to the unique properties of sphere morphology.

It is well known that particles in nanoscaled have large surface area. The large surface area has serious drawbacks in PL intensity due to the introduction of a large number of defects into the phosphor crystal. Defects have serious implications for luminescent materials as they provide non-radiative recombination routes for electrons and holes.[13] As the surfactant was adopted in the hydrothermal procedure, the defects of the phosphor decreased, which induced the increase in the PL intensity. Additionally, the spherical shape diminished light scattering as mentioned above, which resulted in the PL intensity of nanospherical $\mathrm{Zn}_{2} \mathrm{SiO}_{4}$ : $\mathrm{Mn}^{2+}$ phosphor being maximized. When excessive surfactant was adopted, the particles smaller than several nanometers agglomerated, and the PL intensity decreased for the increased surface defects as non-radiative recombination routes. This is the reason that PL intensity changed with different morphology.

\section{3 $\mathrm{BaMgAl}_{10} \mathrm{O}_{17}: \mathrm{Eu}^{2+}$ blue nano-phosphor}

Figure 7 shows the typical XRD patterns of the sol-gel derived $\mathrm{BaMgAl}_{10} \mathrm{O}_{17}: \mathrm{Eu}^{2+}$ samples prepared at different reaction temperatures for $4 \mathrm{~h}$. At $850^{\circ} \mathrm{C}$, the sample is amorphous. When the temperature rises to $1200^{\circ} \mathrm{C}$, the $\mathrm{BAM}$ phase begins to form but still has an impurity peak $\left(\mathrm{BaAl}_{2} \mathrm{O}_{4}\right)$. Farther rising to $1250^{\circ} \mathrm{C}$, the impurity peak disappeared and forms a well BAM phase. It matches well with JCPDS card (No. 26-0163) of BAM with $\beta$ alumina structure corresponding to the space group $\mathrm{P}_{3} / \mathrm{mmc}$. When the temperature rises to $1300^{\circ} \mathrm{C}$, it is also single-phase with the crystallinity much improved. On the contrary to this technique,

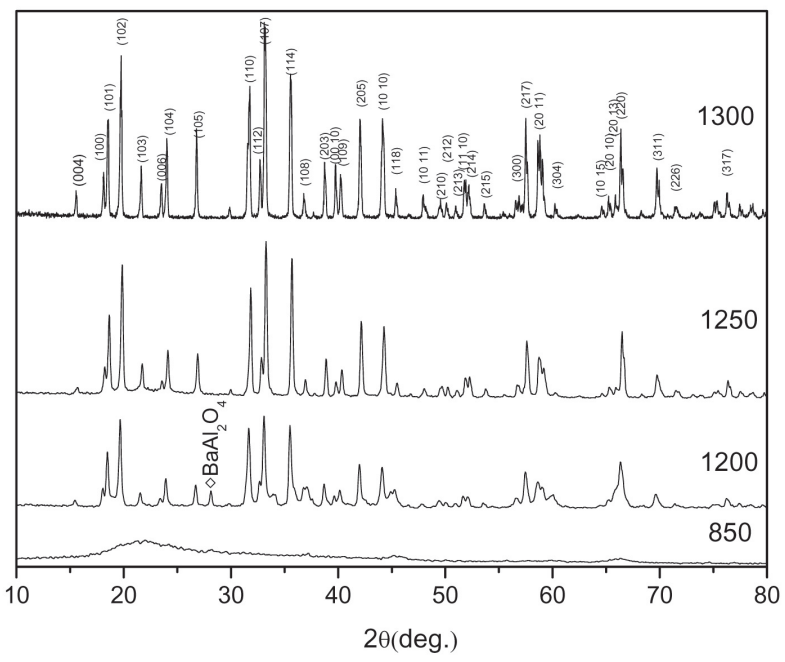

Figure 7 XRD patterns for $\mathrm{BaMgAl}_{10} \mathrm{O}_{17}: \mathrm{Eu}^{2+}$ prepared at different reaction temperatures. 
in conventional solid-state reaction, the presence of intermediates was identified which brought on impurities in the product even at the temperature of $1600^{\circ} \mathrm{C}$.

As shown in Figure 8, the images exhibit the SEM micrographs of the BAM samples under $1250^{\circ} \mathrm{C}$ (a) and $1300^{\circ} \mathrm{C}$ (b). As $\mathrm{BaMgAl}_{10} \mathrm{O}_{17}$ has the crystal structure of $\beta$-alumina, the particle takes the form of hexagonal platelets when the crystal freely grows ${ }^{[14]}$. In the images of (a) and (b), the nanorods could be
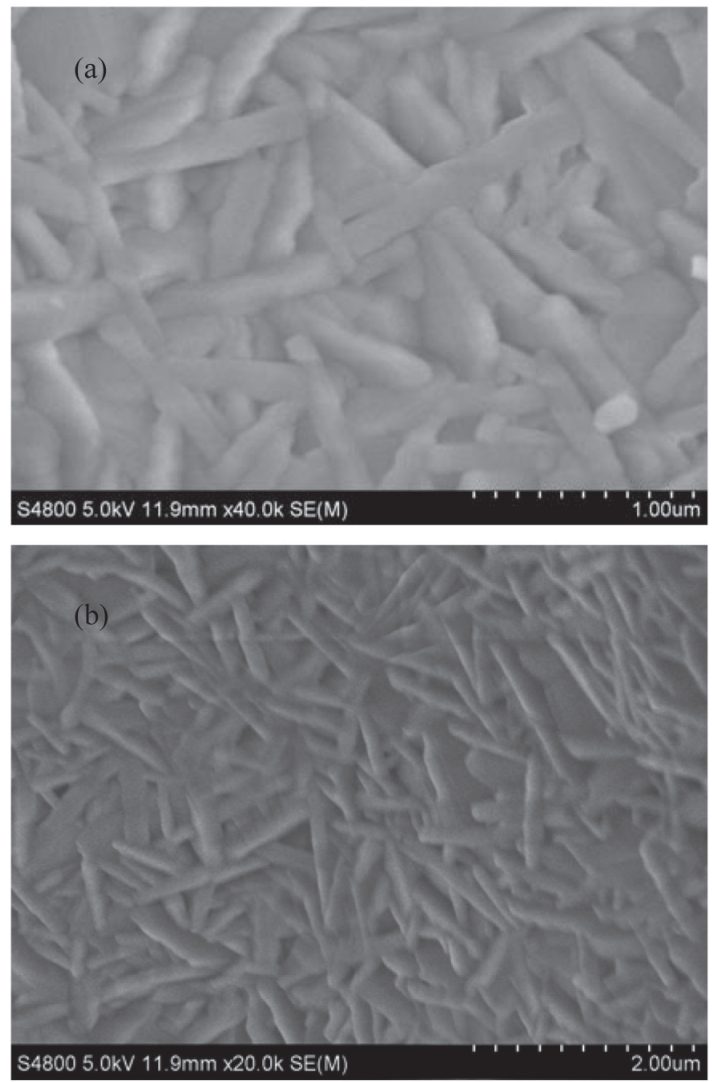

Figure 8 SEM images of BAM phosphors synthesized at (a) $1250^{\circ} \mathrm{C}$, (b) $1300^{\circ} \mathrm{C}$

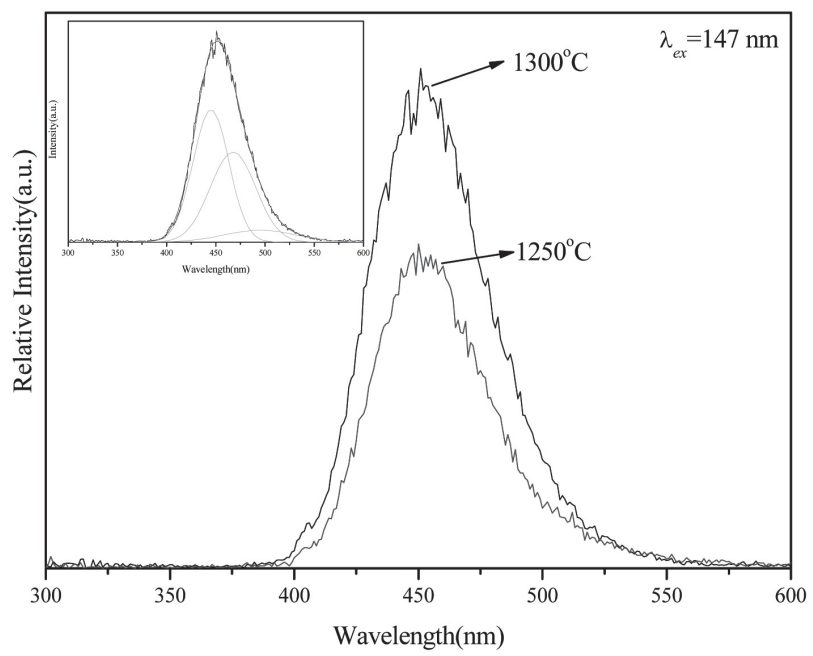

Figure 9 Emission spectra of $\mathrm{BaMgAl}_{10} \mathrm{O}_{17}: \mathrm{Eu}^{2+}$ blue nano-phosphors synthesized by sol-gel method under $1250^{\circ} \mathrm{C}$ and $1300^{\circ} \mathrm{C}\left(\lambda_{\text {ex }}=\right.$ $147 \mathrm{~nm}$ ); the inset is Gaussian fitted emission spectrum of BAM.
Table 1 The ratio of emission intensity and color coordinates of the tricolor nano-phosphor compared with commercial phosphor

\begin{tabular}{llll}
\hline \hline Nano-scaled phosphor & $\mathrm{YBO}_{3}: \mathrm{Eu}^{3+}$ & $\mathrm{ZnSiO}_{4}: \mathrm{Mn}^{2+}$ & $\mathrm{BaMgAl}_{10} \mathrm{O}_{17}:$ \\
& & & $\mathrm{Eu}^{2+}$ \\
\hline Ratio (compared with commercial phosphor) & $78.8 \%$ & $86 \%$ & $78.15 \%$ \\
\hline Color coordinates of nano-scaled phosphor & $(0.644,0.356)$ & $(0.219,0.646)$ & $(0.143,0.068)$ \\
\hline Color coordinates of commercial phosphor & $(0.645,0.355)$ & $(0.248,0.649)$ & $(0.144,0.069)$ \\
\hline Color coordinates of NTSC & $(0.67,0.33)$ & $(0.21,0.71)$ & $(0.147,0.08)$
\end{tabular}

obviously seen and has a homogeneous grain size at $80-100 \mathrm{~nm}$ in diameter and $0.8-1 \mu \mathrm{m}$ in length. In addition, we can also observe that the nano-rods are of well dispersion and maintain the morphology when the temperature rises from $1250^{\circ} \mathrm{C}$ to $1300^{\circ} \mathrm{C}$. These results indicate that citric sol-gel process is an effective method for the preparation of nano-scaled phosphor with high dispersion which needs complicated synthesis conditions.

Figure 9. illustrates the comparison of the emission spectra of BAM nano-phosphors synthesized by sol-gel method under $1250^{\circ} \mathrm{C}$ and $1300^{\circ} \mathrm{C}$ by $147 \mathrm{~nm}$ excitation. On account of the $5 \mathrm{~d}$ orbital of $\mathrm{Eu}^{2+}$ is easily split insomuch the influence of the crystal field ${ }^{[15]}$, the emission spectrum of BAM nano-phosphor in Figure 9 presents a broad band locating at about $452 \mathrm{~nm}$, and it could be attributed to the $4 \mathrm{f}^{6} 5 \mathrm{~d} \rightarrow 4 \mathrm{f}^{7}\left({ }^{8} \mathrm{~S}_{7 / 2}\right)$ transition of $\mathrm{Eu}^{2+[16]}$. Moreover, the emission band is of asymmetrical distribution. This relates to the different sites of $\mathrm{Eu}^{2+}$ occupied in BAM. By Gaussian fitting the VUV emission spectrum (as shown in the inset of Figure 9), three peaks were found and these peaks located at $446 \mathrm{~nm}, 477 \mathrm{~nm}$ and $517 \mathrm{~nm}$, corresponding to the emission of $\mathrm{Eu}^{2+}$ in the sites of BR, a-BR and spinel layer ${ }^{[17-18]}$. With the temperature increasing from $1250^{\circ} \mathrm{C}$ to $1300^{\circ} \mathrm{C}$, the emission intensity of these nano-phosphors by $147 \mathrm{~nm}$ excitation enhanced about $22 \%$. The improvement of the emission could be ascribed to the improvement of the crystallinity as discussed in Figure 7.

\subsection{Comparison to commercial phosphor}

Table 1 shows the ratio of emission intensity and the color coordinates of the tri-color nano-phosphor compared with commercial phosphor. The emission intensity of nano-scaled $\mathrm{YBO}_{3}: \mathrm{Eu}^{3+}, \mathrm{ZnSiO}_{4}: \mathrm{Mn}^{2+}$ and $\mathrm{BaMgAl}_{10} \mathrm{O}_{17}: \mathrm{Eu}^{2+}$ reaches $78.8 \%, 86 \%, 78.15 \%$ respectively compared with the commercial phosphor. The color coordinates of nano-scaled $\mathrm{YBO}_{3}: \mathrm{Eu}^{3+}$ and $\mathrm{ZnSiO}_{4}: \mathrm{Mn}^{2+}$ is superior to commercial bulk phosphor and more close to the National Television Systems Committee (NTSC). For nano-scaled $\mathrm{BaMgAl}_{10} \mathrm{O}_{17}: \mathrm{Eu}^{2+}$, the $y$ value of the coordinates is lower than the value of both commercial phosphor and NTSC which means that it is useful for restricting the decrease of BAM effciency during application.

\section{Conclusion}

$\mathrm{YBO}_{3}: \mathrm{Eu}^{3+}$ nano-sheets, $\mathrm{ZnSiO}_{4}: \mathrm{Mn}^{2+}$ nano-spheres and $\mathrm{BaMgAl}_{10} \mathrm{O}_{17}: \mathrm{Eu}^{2+}$ nano-rods were synthesized by solvent-thermal, hydrothermal and sol-gel processes respectively. By $147 \mathrm{~nm}$ excitation, the $\mathrm{YBO}_{3}: \mathrm{Eu}^{3+}$ nano-sheets exhibit $78.8 \%$ on emission intensity of that of commercial phosphor and better color purity than the latter; $\mathrm{The}_{\mathrm{ZnSiO}}$ : $\mathrm{Mn}^{2+}$ nano-spheres show the strongest 
emission intensity than $\mathrm{ZnSiO}_{4}: \mathrm{Mn}^{2+}$ of other morphologies and reaches $86 \%$ of that of the commercial phosphor; The $\mathrm{BaMgAl}_{10} \mathrm{O}_{17}: \mathrm{Eu}^{2+}$ nano-rods represent $78.15 \%$ of the emission intensity of commercial phosphor, and obtained low $y$ value of the BAM nano-rods suggesting that it was helpful for enhancing the thermal stability. All of the results indicated that the tricolor nanoscaled phosphors had an optimistic application prospect in PDPs.

Acknowledgements: This work is supported by the National Natural Science Foundation of China (No. 10874061), the Project of the combination of Industry and Research by the Ministry of Education and Guangdong Province (Grant No.0712226100023) and the Research Fund for the Doctoral Program of Higher Education (RFDP, No.200807300010).

Note: In this paper, the data of $\mathrm{YBO}_{3}: \mathrm{Eu}^{3+}$ nano-phosphor is provided by Qizheng Dong, the data of $\mathrm{ZnSiO}_{4}: \mathrm{Mn}^{2+}$ nanophosphor is provided by Xue $\mathrm{Yu}$, and the data of $\mathrm{BaMgAl}_{10} \mathrm{O}_{17}$ : $\mathrm{Eu}^{2+}$ nano-phosphor is provided by Zhaofeng Wang.

\section{References}

[1] Jung, I. Y., Cho, Y., Lee S. G. and Sohn, S. H., Appl. Phy. Lett., Vol.87, pp.191908, (2005)

[2] Kim, K. B., Koo, K. W., Cho T. Y., and Chun, H. G., Mater. Chem. Phys., Vol.80, pp.682, (2003)

[3] Wang, Y. H. and Li, F., J. Lumin., Vol.122-123, pp.866-868, (2007).

[4] Zhou, Y., Lin, J., Yu, M., Wang, S. and Zhang, H., Mater. Lett., Vol.56, pp.628, (2002).
[5] Yin, S., Inoue, Y., Uchida, S., Fujishiro, Y. and Sato, T., J. Mater. Res., Vol.13, pp.844-847, (1998).

[6] Yin, S., Aita, Y., Komatsu, M., Wang, J., Tang, Q. and Sato, T., J. Mater. Chem., Vol.15, pp.674-682, (2005).

[7] Wegh, R. T., Donker, H., Oskam, K. D. and Meijerink, A., Science Vol.283, pp.663, (1999).

[8] Maas, H., Currao, A. and Calzaferri, G., Angew. Chem. Int. Ed., Vol.41, pp.2495, (2002).

[9] Wei, Z., Sun, L., Liao, C., Yan, C. and Huang, S., Appl. Phys. Lett., Vol.80, pp.1447-1449, (2002).

[10] Wang, H. F., Ma, Y. Q., Yi, G. S. and Chen, D. P., Mater. Chem. Phys., Vol.82, pp.414, (2003).

[11] Wan, J. X., Chen, X. Y., Wang, Z. H., Mu, L. and Qian, Y. T, J. Crystal Growth, Vol.280, pp.239, (2005).

[12] Cheng, H. M., Ma, J. M., Zhao, Z. G. and Qui, L. M., Chem. Mater., Vol.7, pp.663, (1995).

[13] Wakefield, G., Holland, E., Dobson, P. J. and Hutchison, J. L., Adv. Mater., Vol.13, pp.1557, (2001).

[14] Ravichandran, D., Johnson, S. T. and Taya, S., J. Non-Cryst. Solids., Vol.351, pp.697, (2005).

[15] Ronda, C.R. and Smets, B.M.J., J. Electrochem. Soc., Vol.136(2), pp.570-573, (1989).

[16] Blasse, G. and Geiabmaier, B. C., "Luminescent materials," [M]. Springer-Verlag, Berlin, (1994).

[17] Boolchand, P., Mishra, K.C., Raukas, M., Ellens, A. and Schmidt, P.C., Phys. Rev. B, Vol.66, pp.134429, (2002).

[18] Pike, V., Patraw, S., Diaz, A.L. and DeBoer, B.G., J. Solid State Chem., Vol.173, pp.359-366, (2003). 